\title{
Operative Management of Intraventricular Central Neurocytomas: An Analysis of a Surgical Experience with 32 Cases
}

\author{
Li-Feng $\mathrm{CHEN}^{1^{*}}$, Yang YANG ${ }^{2}$, Xiao-Dong MA¹, Xin-Guang YU ${ }^{1}$, Bai-Nan XU11, Ding-Biao ZHOU ${ }^{1}$ \\ ${ }^{1}$ The Chinese PLA General Hospital, Department of Neurosurgery, Beijing, China \\ ${ }^{2}$ The Chinese PLA General Hospital, Department of Geriatric Neurology, Beijing, China \\ *These authors have contributed equally to the manuscript.
}

\section{ABSTRACT}

AIM: To better understand the clinical characteristics of central neurocytoma (CN), as well as to assess the optimum therapeutic schedule.

MATERIAL and METHODS: This was a retrospective study of 32 patients with CN who visited our department between January 2008 and January 2013. We analyzed the clinical and radiological presentations, tumor characteristics, surgical strategies, and the prognosis.

RESULTS: We performed operation guided by combined intraoperative magnetic resonance imaging (iMRI) and neuronavigation in 25 patients. The iMRI detected residual tumor in 9 cases, and further resection was performed in 5 cases. Total and nearly total tumor resection was achieved in 29 cases (91\%). There was no significant difference between transcortical and transcallosal approaches in complications. Two cases (6\%) with recurrence received respectively repeat salvage surgery and radiosurgery at 46 and 50 months after surgery. Thirty patients (94\%) had excellent functional outcome (Karnofsky Performance Score $\geq 80$ ) and 28 patients (88\%) resumed their occupations.

CONCLUSION: Our study demonstrates radical surgery with excellent neurological outcomes is the primary treatment of CN. The techniques of resection guided by combined iMRI and neuronavigation seems to enable a higher complete resection rate and reduce the morbidity rate during surgery. We suggest careful clinical observation after initial surgery, and repeat salvage surgery or radiosurgery for recurrent $\mathrm{CN}$.

KEYWORDS: Central neurocytoma, Neuronavigation, Surgery, Transventricular approach, Radiosurgery

\section{INTRODUCTION}

Central neurocytomas (CNs) are rare brain tumors of young adults, typically located in deep midline structures near the foramen of Monro (28). The tumors were first described as a distinct clinicopathologic entity by Hassoun et al. in 1982 $(9,11)$. These well-differentiated tumors with neuronal differentiation have an indolent clinical course. Gross total resection (GTR) is the first optimal treatment option for most patients with central neurocytoma (CN) (11). However, the proximity to the deep critical neural and vascular structures and rich blood supply increase the risk of surgical treatment. Resection of $\mathrm{CN}$ is still a challenging procedure for most neurosurgeons. The best selection of the common surgical approaches including transcortical transventricular approach and interhemispheric-transcallosal transventricular approach is still controversial, and the optimal selection and timing of adjuvant radiotherapy and chemotherapy also remain unclear. 
As $\mathrm{CN}$ is rare, it is very difficult to collect many cases in a short period in one institution, and histological diagnosis and treatment strategies may evolve during the period of the study. Between January 2008 and January 2013, we performed microsurgery in 32 patients with $\mathrm{CN}$. We reviewed our therapeutic strategies and postoperative follow-ups by retrospective analysis in the present study. The aim was to better understand the clinical and radiological presentation, tumor characteristics, surgical strategies, adjuvant therapy and the prognosis, as well as to assess the optimum therapeutic schedule.

\section{MATERIAL and METHODS}

\section{Patients}

During a 5-year period between January 2008 and January 2013, 32 consecutive patients with histologically verified CN were treated in the Department of Neurosurgery of our hospital by the senior neurosurgeons. All of the 32 patients provided informed consent. Seven cases were operated from January 2008 to January 2009, and five of the 7 cases were operated with a neuronavigation (BrainLab, Germany) system. A dualroom intraoperative magnetic resonance imaging (iMRI) suite with a scanner with a movable 1.5-T magnet (Siemens Espree, Erlangen, Germany) was installed at our center in February 2009 (5). We performed the operation guided by combined iMRI (Siemens Espree, Erlangen, Germany) and neuronavigation (BrainLab, Germany) in the other 25 patients from February 2009 to January 2013. The clinical information was obtained from hospital charts, clinic notes, and operative reports.

\section{Patient Evaluation}

The patients underwent radiological assessment of their lesions by computed tomography (CT) and magnetic resonance imaging (MRI). Tumor size was defined as the greatest contrast-enhancing tumor diameter on MRI. All patients received postoperative follow-up by neuroimaging and neurological examinations. The neurological function and neuroimaging evaluations of the patients were recorded preoperatively, at 3 months postoperatively, and at 1 year to 5 years intervals after surgery. Gross total resection (GTR) was defined as $100 \%$ macroscopic resection of the tumor; nearly total resection (NTR) was close to total resection, but an intended incomplete resection; Subtotal resection (STR) was defined as removal of $<100 \%$ but $>90 \%$. A Karnofsky performance status score (KPS) was also determined for each patient based on clinical evaluations.

\section{Surgical Approaches and Surgical Techniques}

The surgery was performed with general anaesthesia. The details of the iMRI scans were the same as reported in our previous reports $(5,22)$. The surgical approaches include the interhemispheric transcallosal approach and the transcortical approach. A conventional right frontal craniotomy was performed with the patient in the supine position (Figure 1A). After the dural opening, we used the operating microscope. The frontal lobe and falx cerebri were slightly retracted laterally via the interhemispheric transcallosal approach (Figure 1B). The middle frontal gyrus was penetrated via the transcortical approach and the corpus callosum was dissected via the interhemispheric transcallosal approach guided by neuronavigation. Most tumors arose from the septum pellucidum and extended into the lateral ventricles, and generally had a good interface of cleavage from the ependyma of the ventricular walls, but were seen to merge with the septum pellucidum (21). We precisely differentiated and dissected the interface between the tumor surface and the normal tissue of the ventricular wall guided by neuronavigation. Piecemeal tumor resection with the cavitron aspirator was recommended. Most tumors were high vascular, friable in consistency, and associated with quite profuse bleeding. It was necessary to differentiate and protect the main draining vein early (Figures 1C, D). Keeping the operative field clear with gradually debulking the tumor was also very important. When the surgeon believed that the tumor was completely resected, iMRI was performed. If residual tumor was detected, the surgeon would continue resection until subsequent iMRI confirmed complete resection. We retained a ventricular drain in all patients of $\mathrm{CN}$, which was usually removed 48 hours after surgery once the draining cerebrospinal fluid (CSF) became clear and we then clipped the ventricular drain for 24 hours.

\section{Comparisons and Statistical Method}

Seven patients with $\mathrm{CN}$ treated without the iMRI system from January 2008 to January 2009 were reviewed as the control group. Comparisons between the iMRl-assisted group and the control group were focused on age, tumor size, surgical approach, the extent of resection, operation time, operationrelated dysfunction, and tumor recurrence. Comparisons between the two surgical approaches were focused on the extent of resection and postoperative complication. Fisher's exact test (two-tailed) or Student's test (t test) was used. $\mathrm{P}<0.05$ was considered significant. Statistical analysis was performed with the SPSS software version 19 (SPSS version 19, SPSS Inc.).

\section{RESULTS}

\section{Preoperative Characteristics}

The patient demographics and the presenting symptoms are shown in Table I.

There were $25 \mathrm{CT}$ scans and $32 \mathrm{MRI}$ scans available in this study. On the CT scans, the tumors were either isodense or mild hyperdense (Figure 2A, Figure 3A). All the tumors showed moderate or strong enhancement on contrast-enhanced MRI in this series (Figures 2B,C, Figures 3B,C). Three patients $(9 \%)$ had tumors smaller than $3 \mathrm{~cm}, 18$ patients $(56 \%)$ had tumors between 3 and $5 \mathrm{~cm}$, and the other 11 patients (34\%) had tumors larger than $5 \mathrm{~cm}$. Other radiological features are described in Table I.

\section{Surgical Characteristics and Pathology}

All the patients initially underwent surgery, and the postoperative improvements of the symptoms are listed in Table I. The first iMRI scan detected residual tumor in 9 

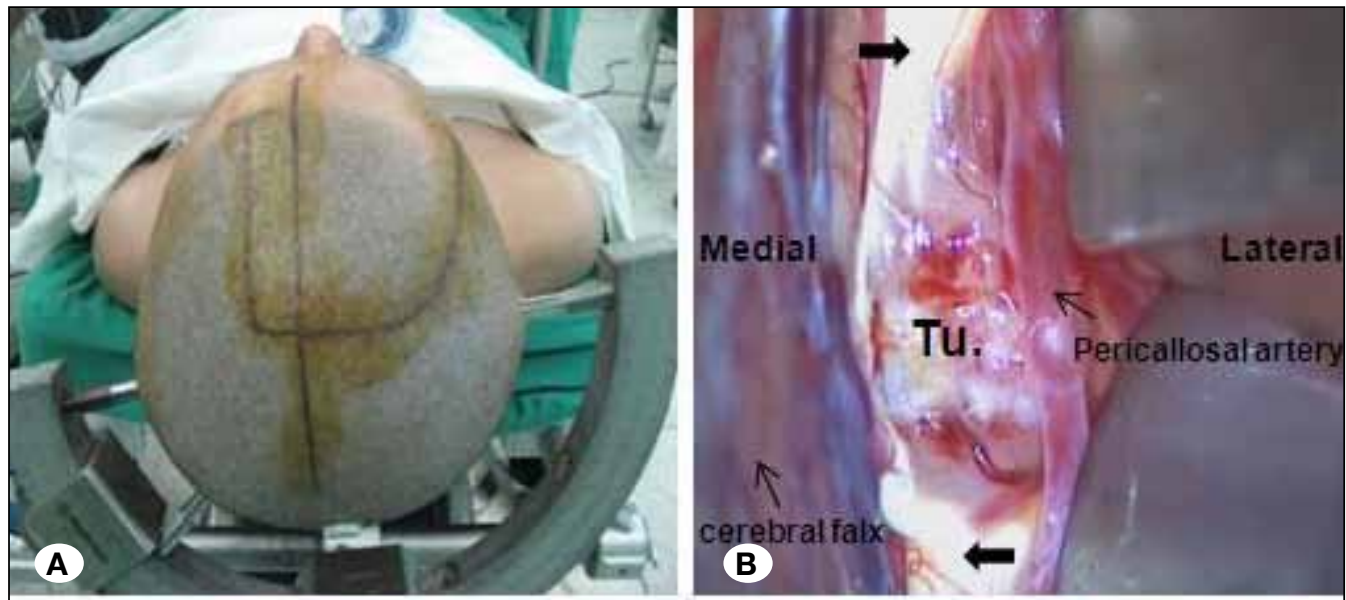

Figure 1: Intraoperative photographs of the central neurocytoma removal showing:
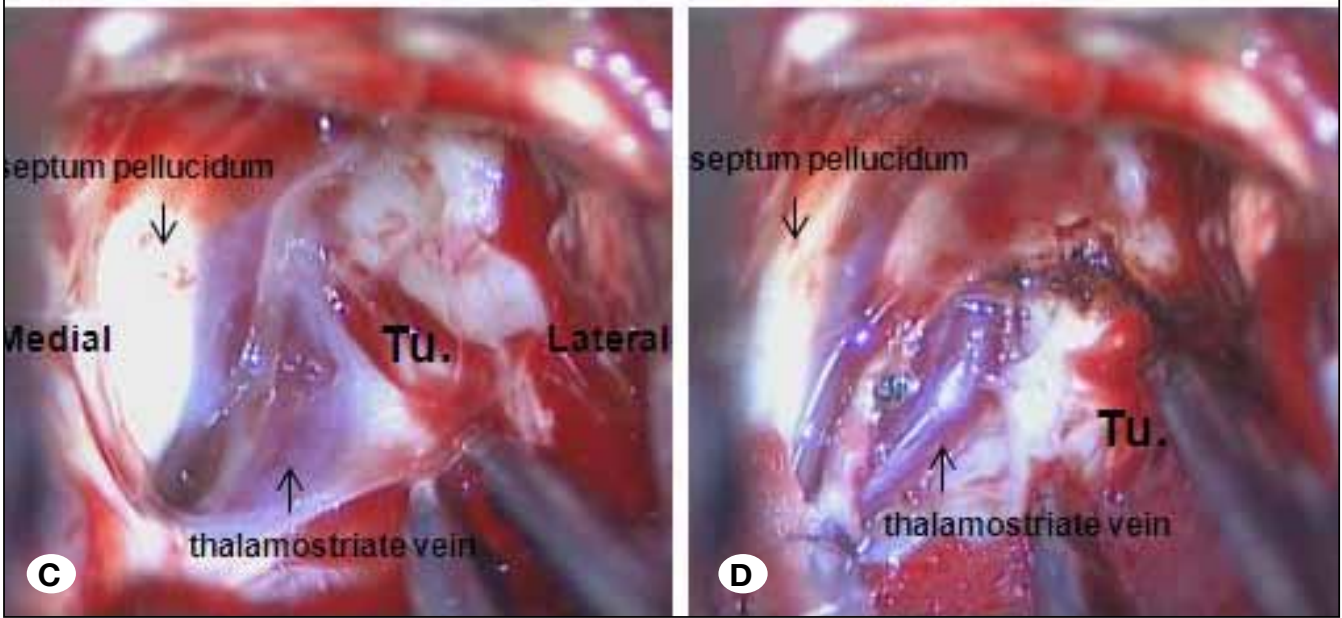

A) A conventional right frontal craniotomy was performed with the patient in the supine position; B) The right frontal lobe and falx cerebri were slightly retracted laterally via the interhemispheric transcallosal approach. The falx cerebri, right pericallosal artery, corpus callosum (think arrow), and tumor (Tu.) were visible; C) The tumor (Tu.) was adhesive with the thalamostriate vein; $\mathbf{D})$ The complete tumor resection was achieved, and the thalamostriate vein was intact.
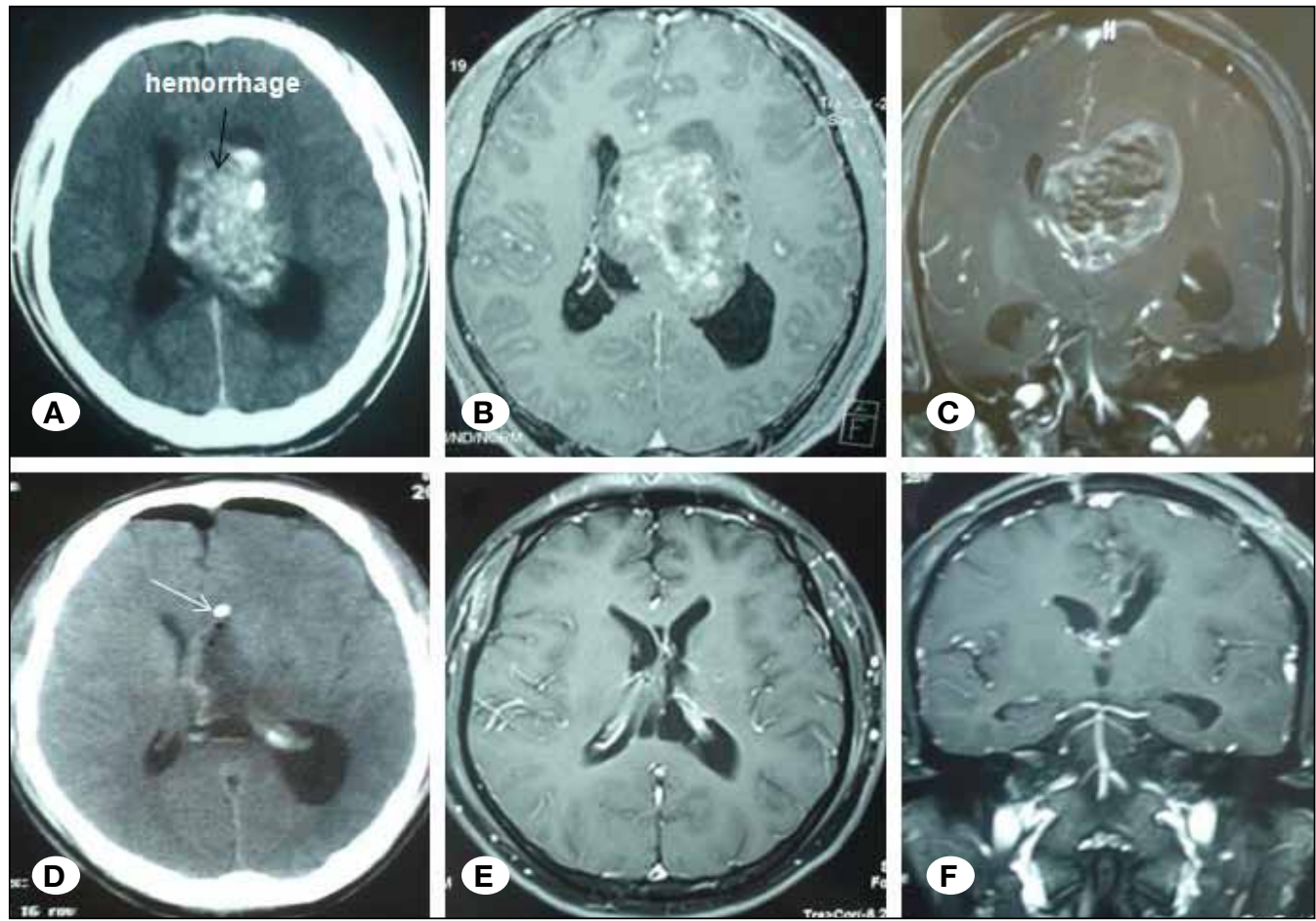

Figure 2: Preoperative

A) CT, B) axial and

C) coronal T1-weighted contrast-enhanced MRI showed a large central neurocytoma, which extended into both lateral ventricles, and the intratumoral hemorrhage could be observed. The patient was operated via the transcortical approach without any complication. D) CT at 1 day after surgery displayed complete tumor removal and the external ventricular drainage tube (write arrow). E) Axial and F) coronal T1weighted contrast-enhanced MRI at 36 months after surgery showed complete tumor removal. 

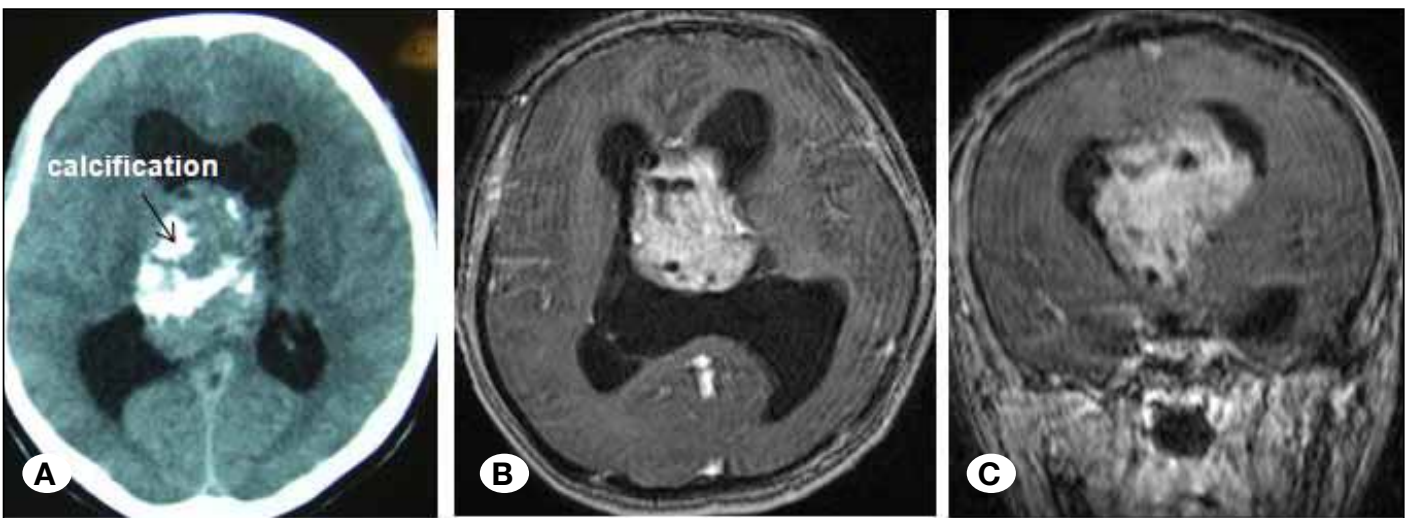

Figure 3: Preoperative A) CT, B) axial and C) coronal T1-weighted contrast-enhanced MRI showed a central neurocytoma, which extended into both
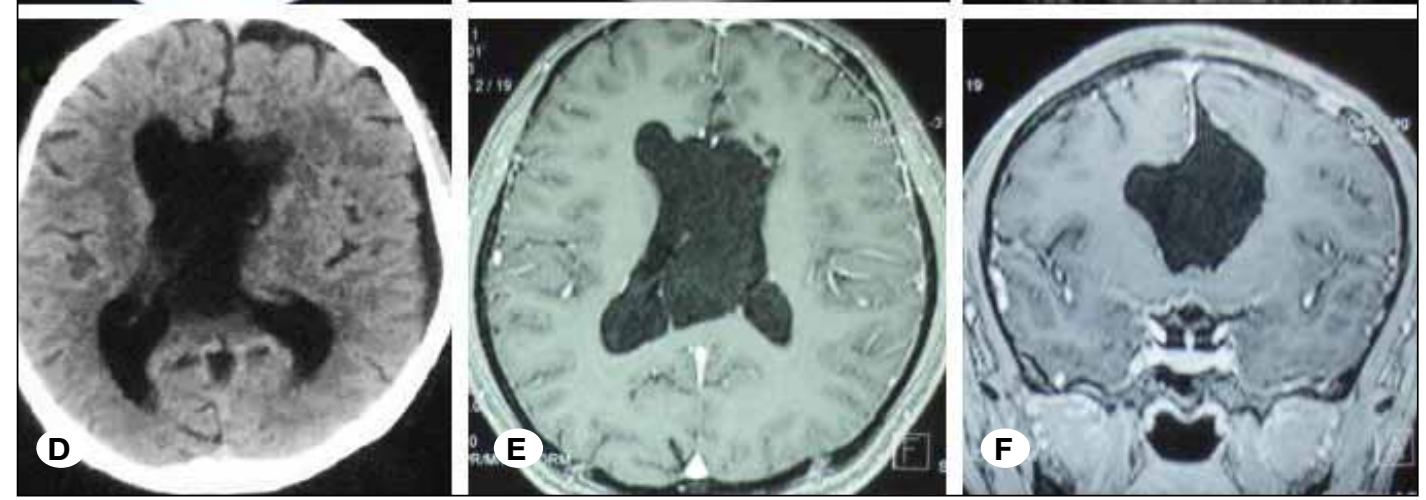

lateral ventricles and the third ventricle. The intratumoral calcification could be observed. The patient was operated via the interhemispheric transcallosal approach without any complication. D) CT, E) axial and F) coronal T1-weighted contrast-enhanced MRI at 48 months after surgery showed complete tumor removal.

of the 25 cases, and the surgeons continued resection in 5 cases with residual tumor until subsequent confirmation of complete resection by repeat iMRI. The major impediment to GTR was the difficulty in dissection from adjacent critical structures, such as the thalamus or thalamostriate vein. The iMRI-assisted group showed a higher rate of total resection of tumor and a lower rate of operation-related dysfunction and tumor recurrence (Table II). The initial extent of tumor removed did not differ significantly according to the two surgical approaches selected (Table III, Figures 2D-F, Figures 3D-F). The details are shown in Tables II and III. The senior neuropathologist verified the histological examinations of all the tumors that were grade II tumors in the WHO classification of tumors.

\section{Postoperative Course}

There was no perioperative mortality. Postoperative symptomatic improvement is shown in Table I, and the operative outcome by two different approaches within 1 month and 6 months after surgery is summarized in Table III. Two patients with CSF infection were successfully treated with lumbar drainage for 5-7 days and intravenous antibiotic administration. There was no difference in surgical complications between the two surgical approaches at the final follow-up. A total of 30 patients (94\%) became independent at 6 months after surgery, and 28 patients $(88 \%)$ resumed their occupations. The KPS scores of the 30 patients ranged from 80 to 100 , and the KPS scores of another two patients were 70 and 60 , respectively. One patient received a permanent shunt because of hydrocephalus.
No patient received adjuvant radiotherapy and chemotherapy after the initial resection. Re-growth was clinically and radiologically observed in 2 patients at 46 and 50 months after the initial resection. Among them, 1 patient who was operated with STR via the transcortical approach underwent repeat surgery, whereas the other one who was operated with STR via the transcallosal approach received adjuvant radiosurgery (Leksell Gamma Knife). The two patients had no recurrence during the additional follow-up period (12 months and 6 months, respectively).

\section{- DISCUSSION}

\section{Epidemiology}

The incidence of $\mathrm{CN}$ is estimated to be only $0.1-0.5 \%$ of all primary brain tumors $(9,16,19,26)$. The tumors typically affect adolescents and young adults with the highest incidence occurring in the third decade. It occurs rarely in people younger than 20 years or older than 40 years of age. Most studies have reported that the patients seem to be equally prevalent in either sex $(9,16,19,26)$. In our series, there was no significant sex variation with the male/female ratio being $1: 1.1$, and the patients ranged from 14 to 59 years of age (mean, 26.3 years). We had 7 patients younger than 20 years and 3 patients older than 40 years.

\section{Clinical Presentation}

CNs usually have a long and benign clinical course. A common presentation of most CNs is hydrocephalus, caused by obstruction of the foramen of Monro by the tumor. The 
Table I: Characteristics in 32 Patients with Central Neurocytomas

\begin{tabular}{|c|c|c|c|}
\hline \multirow{2}{*}{ Characteristics/ Number of Cases } & \multirow{2}{*}{$n=32$} & \multicolumn{2}{|c|}{ Postoperative improvement (\%) } \\
\hline & & Immediate ${ }^{a}$ & Medium term ${ }^{b}$ \\
\hline \multicolumn{4}{|l|}{ Demographics } \\
\hline Mean age, (years) (range) & $26.3(14-59)$ & - & - \\
\hline Sex (male/female) & $15: 17$ & - & - \\
\hline \multicolumn{4}{|l|}{ Tumor features } \\
\hline Mean size, (cm) (range) & $4.8(2.5-5.7)$ & - & - \\
\hline \multicolumn{4}{|l|}{ Tumor location } \\
\hline Unilateral ventricles & $5(16 \%)$ & - & - \\
\hline Both lateral ventricles & $27(84 \%)$ & - & - \\
\hline Third ventricle & $14(44 \%)$ & - & - \\
\hline \multicolumn{4}{|l|}{ Intratumoral texture } \\
\hline Calcification & $19(59 \%)$ & - & - \\
\hline Cystic & $22(69 \%)$ & - & - \\
\hline Hemorrhage & $2(6 \%)$ & - & - \\
\hline Flow void & $17(53 \%)$ & & \\
\hline \multicolumn{4}{|l|}{ Major symptoms and signs } \\
\hline Headache and dizziness & $24(75 \%)$ & $22(92 \%)$ & $24(100 \%)$ \\
\hline Nausea and vomiting & $21(66 \%)$ & $21(100 \%)$ & $21(100 \%)$ \\
\hline Ataxia & $12(38 \%)$ & $10(83 \%)$ & $12(100 \%)$ \\
\hline Visual disturbance & $7(22 \%)$ & $5(71 \%)$ & $6(86 \%)$ \\
\hline Seizure & $3(9 \%)$ & $1(33 \%)$ & $1(33 \%)$ \\
\hline Coma & $1(3 \%)$ & $1(100 \%)$ & $1(100 \%)$ \\
\hline Weakness & $1(3 \%)$ & $0(0 \%)$ & $1(100 \%)$ \\
\hline Hydrocephalus & $26(81 \%)$ & $22(85 \%)$ & $25(96 \%)$ \\
\hline Mean symptoms duration, (months) & 5.5 & - & - \\
\hline Range & 2 days -2 years & - & - \\
\hline Median preoperative KPS ${ }^{\mathrm{c}}$ & 80 & - & - \\
\hline Mean follow-up duration, (months) (range) & $38(12-60)$ & - & - \\
\hline
\end{tabular}

a 1 months after operation in the series; ${ }^{b} 6$ months after operation in the series; ${ }^{c}$ KPS, Karnofsky Performance Scale.

Table II: Comparisons Between the iMRI-Assisted Group and no iMRI-Assisted Group

\begin{tabular}{|c|c|c|c|}
\hline Parameters/ Group & iMRI-assisted Group ( $n=25)$ & No iMRI-assisted group $(n=7)$ & $\mathbf{p}$ \\
\hline Age (years) & $25.3 \pm 14.7$ & $30.4 \pm 6.8$ & 0.192 \\
\hline Mean size $(\mathrm{cm})$ & $4.8 \pm 0.7$ & $4.6 \pm 1.0$ & 0.581 \\
\hline Surgical approach(TCO/TCA $)^{a}$ & $12 / 13$ & $3 / 4$ & $0.576^{b}$ \\
\hline Operation time (hours) & $6.3 \pm 0.7$ & $6.0 \pm 0.7$ & 0.882 \\
\hline Blood loss $\left(\mathrm{cm}^{3}\right)$ & $495 \pm 134.9$ & $489 \pm 123.4$ & 0.148 \\
\hline Total resection & $84 \%(21 / 25)$ & $42.9 \%(3 / 7)$ & $0.047^{b}$ \\
\hline Nearly total & $16 \%(4 / 25)$ & $14.3 \%(1 / 7)$ & - \\
\hline Subtotal & $0(0 / 25)$ & $42.9 \%(3 / 7)$ & - \\
\hline Operation-related dysfunction ${ }^{c}$ & $8 \%(2 / 25)$ & $28.6 \%(2 / 7)$ & $0.201^{b}$ \\
\hline Recurrence & $0(0 / 25)$ & $28.6 \%(2 / 7)$ & $0.042^{b}$ \\
\hline
\end{tabular}

${ }^{a}$ TCO, transcortical; TCA, transcallosal; ${ }^{b}$ Fisher's exact test (two-tailed) was used. Student's test ( $t$ test) was used for others. $P<0.05$ was considered significant; ${ }^{c}$ new neurological deficits or worsening of pre-existing deficits at 6 months after operation in the series. 
symptoms include headaches, nausea-vomiting, seizures, visual impairment, and memory disturbance. The duration of symptoms is usually less than 6 months (4). Intratumoral and/ or intraventricular hemorrhage are also rarely reported (21). In our series, preoperative symptom duration ranged from 2 days to 2 years (mean, 5.5 months). The common symptom was headache, and only two patients $(6 \%)$ had intratumoral hemorrhage.

\section{Radiology}

A typical $\mathrm{CN}$ is usually located in the supratentorial ventricular system, and the anterior half of the lateral ventricle is the most frequent location $(1,7) .26 \%$ of $\mathrm{CNs}$ can extend into the third ventricle, and isolated third or fourth ventricular occurrence, extraventricular sites and craniospinal dissemination are rare $(2,4,17,27)$. The tumor is usually isointense in T1-weighted and T2-weighted images, with a "soap-bubble" appearance in T2-weighted images and there is usually moderate to strong enhancement with contrast (21), and approximately $51 \%$ demonstrate calcification (9). Our series confirmed to the general observation reported above. CT scan revealed calcification in $59 \%$. MRI showed that $69 \%$ of the tumors contained multiple small cysts, 17 tumors (53\%) exhibited evidence of flow voids from tumor vessels on MRI and $44 \%$ of the tumors extended into the third ventricle.

\section{Surgical Approach}

The goals of surgery for $\mathrm{CN}$ are to maximize a safe resection, provide tissue for histological diagnosis and re-establish CSF pathways (24). The selection of the optimal surgical approach should consider the tumor's location, size, expansion, and the degree of hydrocephalus $(16,25)$. Kim et al. (10) reported the initial extent of tumor removed did not differ significantly according to the surgical approach used. The interhemispheric transcallosal approach had a better seizure outcome than did the transcortical approach (15), and there were no differences in other functional outcomes. We selected the surgical approach according to the location and size of the tumor, the degree of hydrocephalus, and the surgeon's preference. Operations of 25 cases were guided by the combined iMRI and neuronavigation in the present study. The neuronavigation helped us to determine the best location for incision of the brain cortex or corpus callosum and minimized surgical injury to the brain. In our series, there were no significant differences in functional outcomes including memory deficit, and motor weakness according to the surgical approach selected. As the interhemispheric transcallosal approach is a natural approach with less damage to the cortical area, we have a slight preference for it.

\section{Surgical Strategy}

As CNs have a deep-seated intraventricular location, an abundant blood supply, and proximity to critical structures such as the fornix and thalamus, the surgical morbidity and mortality rates were relative high $(6,8,10-14,19,23)$. Some reported rates of GTR ranged from $31 \%$ to $88 \%$, mortality rates varied between $0 \%$ and $19 \%$, and morbidity rates varied between $16 \%$ and $52 \%$ (Table IV). GTR was usually associated with high morbidity and mortality rates. Some authors $(10,11,19)$ advocated that GTR should not be pursued at all costs, and that the patient's quality of life and tumor control should be the ultimate strategies of treatment. We agreed with them, and we incurred a $91 \%$ radical removal rate with a permanent postoperative morbidity rate of $13 \%$. The better outcome (Table IV) in our series seemed to be attributed to the combined iMRI and neuronavigation system. When the ventricle was opened and CSF flowed out, brain shifts were usually detected during the operation of the intraventricular tumor. This can be resolved by the combined iMRI and neuronavigation. After the main part of the tumor was removed, iMRI was used to update the neuronavigation after the brain shift and enabled the more accurate recognition

Table III: Operative Outcome of 32 Patients with Central Neurocytomas $^{a}$

\begin{tabular}{|c|c|c|c|}
\hline Parameters/ Approach & $\begin{array}{c}\text { TCO } \\
(n=15)\end{array}$ & $\begin{array}{c}\text { TCA } \\
(n=17)\end{array}$ & $\mathbf{P}^{\mathrm{b}}$ \\
\hline \multicolumn{4}{|l|}{ Extent of resection } \\
\hline Total & 11 & 13 & 0.579 \\
\hline Nearly total & 3 & 2 & - \\
\hline Subtotal & 1 & 2 & - \\
\hline \multicolumn{4}{|l|}{ Hydrocephalus } \\
\hline Immediate $^{\mathrm{c}}$ & 2 & 1 & 0.452 \\
\hline Medium term $^{d}$ & 1 & 0 & 0.469 \\
\hline \multicolumn{4}{|l|}{ Memory deficit } \\
\hline Immediate $^{\mathrm{c}}$ & 1 & 3 & 0.452 \\
\hline Medium term ${ }^{d}$ & 1 & 1 & 0.726 \\
\hline \multicolumn{4}{|l|}{ Seizure } \\
\hline Preoperative & 2 & 1 & - \\
\hline Medium term $^{d}$ & 1 & 1 & 0.726 \\
\hline \multicolumn{4}{|l|}{ Weakness } \\
\hline Immediate $^{c}$ & 1 & 1 & 0.726 \\
\hline Medium term ${ }^{d}$ & 1 & 1 & 0.726 \\
\hline \multicolumn{4}{|l|}{ Infection } \\
\hline Immediate $^{c}$ & 1 & 1 & 0.726 \\
\hline Medium term ${ }^{d}$ & 0 & 0 & - \\
\hline \multicolumn{4}{|l|}{ Median postoperative KPS } \\
\hline Immediate $^{c}$ & 80 & 80 & - \\
\hline Medium term ${ }^{d}$ & 90 & 90 & - \\
\hline Postoperative death & 0 & 0 & $0(0 \%)$ \\
\hline
\end{tabular}

aTCO, transcortical; TCA,transcallosal; KPS, Karnofsky Performance Scale; 'b Fisher's exact test (two-tailed) was used. $P<0.05$ was considered significant; " 1 month after operation in the series; ${ }^{d} 6$ months after operation in the series. 
Table IV: Some of the Major Retrospective Series on Central Neurocytomas $(n>15)$

\begin{tabular}{|c|c|c|c|c|c|c|c|}
\hline Author \& Year & $\begin{array}{c}\text { Cases } \\
\text { (n) }\end{array}$ & $\begin{array}{c}\text { Radical } \\
\text { removal (\%) }\end{array}$ & $\begin{array}{c}\text { Mortality } \\
\text { (\%) }\end{array}$ & $\begin{array}{c}\text { Morbidity } \\
(\%)^{a}\end{array}$ & $\begin{array}{c}\text { Follow-up } \\
\text { (months) } \\
\text { Mean(range) }\end{array}$ & $\begin{array}{l}\text { Recurrence } \\
\text { rate }(\%)\end{array}$ & $\begin{array}{l}\text { Survival } \\
\text { rate (\%) }\end{array}$ \\
\hline Figarella-Branger et al. 1992, (6) & 20 & $9(45 \%)$ & $10 \%$ & ND & $36(6-108)$ & ND & $70 \%$ \\
\hline Schild et al. 1997, (23) & 32 & $10(31 \%)$ & $9 \%$ & ND & $56(28-184)$ & ND & $91 \%$ \\
\hline Mackenzie 1999, (13) & 15 & $8(53 \%)$ & $0 \%$ & ND & $68(13-255)$ & $20 \%$ & $93 \%$ \\
\hline Mena et al. 2001, (14) & 32 & $12(38 \%)$ & $19 \%$ & ND & $93(11-204)$ & $4 \%$ & $65 \%$ \\
\hline Lenzi et al. 2006, (12) & 20 & $10(50 \%)$ & $10 \%$ & $20 \%$ & $84(9-136)$ & $35 \%$ & $90 \%$ \\
\hline Leenstra et al. $2007,(11)$ & 45 & $21(47 \%)$ & $7 \%$ & ND & $120(19-280)$ & $33 \%$ & $80 \%$ \\
\hline Hallock et al. 2011, (8) & 19 & $10(53 \%)$ & $5 \%$ & $16 \%$ & $105(1-262)$ & $32 \%$ & $89 \%$ \\
\hline Qian et al. 2012, (19) & 92 & $65(71 \%)$ & $3 \%$ & $40 \%$ & $43(6-84)$ & $4 \%$ & $97 \%$ \\
\hline Kim et al. 2013, (10) & 48 & $42(88 \%)$ & $2 \%$ & $52 \%$ & $119(18-304)$ & $13 \%$ & $90 \%$ \\
\hline Chen 2014 (present series) & 32 & $29(91 \%)$ & $0 \%$ & $13 \%$ & $38(12-60)$ & $6 \%$ & $100 \%$ \\
\hline
\end{tabular}

a 6 months after operation in the series. ND: not described.

of tumor borders and avoidance of important structures. The rate of operation-related dysfunction was $8 \%$ in the iMRIassisted group, and $28.6 \%$ in the no iMRI-assisted group. Though the statistical result was not significant, it may still imply an advantage.

IMRI also helped to detect residual tumor and achieve radical removal. IMRI was used to detect the residual tumor in 9 of the 25 patients and the surgeon continued resection in 5 cases with residual tumor until subsequent confirmation of complete resection by repeat $\mathrm{iMRI}$ in the present study. We achieved $84 \%$ of GTR and $16 \%$ of NTR in the iMRI-assisted group, higher than that of the iMRI-unassisted group. In contrast to Qian et al.'s report (19), calcifications seemed not to act against GTR, and the major impediment to GTR was adherence to the critical structures including thalamus or thalamostriate vein in our series. If there were difficulties in dissection from the critical structures, STR should be recommended.

\section{Complications}

The main reported complications included hydrocephalus, memory deficit, paresis, epidural hematoma, seizure, and intracranial infection $(6,8,10-14,19,23)$. Among them, hydrocephalus is the most common complication. In our series, only one postoperative patient with the non-obstructive hydrocephalus received a ventriculoperitoneal shunt. Decreased memory is most probably caused by injury to the corpus callosum and fornix or hydrocephalus. We emphasize that the length of dissected corpus callosum should be less than $3 \mathrm{~cm}$. In our series, 2 patients had permanent memory deficits, and $88 \%$ of the patients returned to work during follow-up.

\section{Treatment Options}

Because of the rarity of $\mathrm{CN}$, no randomized clinical trials and few prospective studies have been done, and the optimal management strategies are still evolving. The question of further treatment for residual and recurrent tumors remains controversial (3). Conventional radiotherapy is not theoretically necessary for most of the tumors because of their benign indolent clinical course. Moreover, the experiences in radiotherapy are still limited, and the long-term effect that induces cognitive dysfunction and other potential radiation toxicity cannot be ignored (18). Rades and Fehlauer (20) reported significant improvement in the 5-year local control rate with adjuvant radiosurgery after STR (83\%) compared with STR alone in a meta-analysis of data from 310 patients. They suggested that postoperative radiosurgery should be administered after STR in all patients to avoid the risks associated with a second resection and concerns regarding craniospinal dissemination. We recommend a "wait-and-see" strategy for asymptomatic residual $\mathrm{CNs}$. We advocate reoperation or radiosurgery for recurrent CNs. In our series, 2 patients who were operated with STR had recurrence. Among them, one patient received adjuvant radiosurgery, and another one received reoperation. The two patients had no recurrence during the additional follow-up period. There is no study performed to prove the effect of adjuvant chemotherapy. We do not recommend adjuvant chemotherapy for the patients.

\section{CONCLUSION}

Our study demonstrates that radical surgery is the primary treatment of $\mathrm{CN}$ with its excellent neurological outcomes. The techniques of resection guided by combined iMRI and neuronavigation seems to enable a higher complete resection rate and reduce the morbidity rate during surgery. We suggest careful clinical observation after initial surgery, and repeat salvage surgery or radiosurgery for recurrent $\mathrm{CN}$. 


\section{REFERENCES}

1. Aker FV, Ozkara S, Eren P, Peker O, Armağan S, Hakan T: Cerebellar liponeurocytoma/lipidized medulloblastoma. J Neurooncol 71:5359, 2005

2. Ashkan K, Casey AT, D'Arrigo C, Harkness WF, Thomas DG: Benign central neurocytoma. Cancer 89:1111-1120, 2000

3. Bertalanffy A, Roessler K, Koperek O, Gelpi E, Prayer D, Knosp E: Recurrent central neurocytomas. Cancer 104:135-142, 2005

4. Chen CL, Shen CC, Wang J, Lu CH, Lee HT: Central neurocytoma: A clinical, radiological and pathological study of nine cases. Clin Neurol Neurosurg 110:129-136, 2008

5. Chen X, Xu BN, Meng X, Zhang J, Yu X, Zhou D: Dualroom 1. 5-T intraoperative magnetic resonance imaging suite with a movable magnet: Implementation and preliminary experience. Neurosurg Rev 35:95-109, discussion 109-110, 2012

6. Figarella-Branger D, Pellissier JF, Daumas-Duport C, Delisle MB, Pasquier B, Parent M, Gambarelli D, Rougon G, Hassoun J: Central neurocytomas. Critical evaluation of a small-cell neuronal tumor. Am J Surg Pathol 16:97-109, 1992

7. Goergen SK, Gonzales MF, McLean CA: Interventricular neurocytoma: Radiologic features and review of the literature. Radiology 182:787-792, 1992

8. Hallock A, Hamilton B, Ang LC, Tay KY, Meygesi JF, Fisher BJ, Watling CJ, Macdonald DR, Bauman GS: Neurocytomas: Longterm experience of a single institution. Neuro Oncol 13:943-949, 2011

9. Hassoun J, Soylemezoglu F, Gambarelli D, Figarella-Branger D, von Ammon K, Kleihues P: Central neurocytoma: A synopsis of clinical and histological features. Brain Pathol 3:297-306, 1993

10. Kim JW, Kim DG, Kim IK, Kim YH, Choi SH, Han JH, Park CK, Chung HT, Park SH, Paek SH, Jung HW: Central Neurocytoma: Long-term outcomes of multimodal treatments and management strategies based on 30 years' experience in a single institute. Neurosurgery 72:407-413, discussion 413-414, 2013

11. Leenstra JL, Rodriguez FJ, Frechette CM, Giannini C, Stafford SL, Pollock BE, Schild SE, Scheithauer BW, Jenkins RB, Buckner JC, Brown PD: Central neurocytoma: Management recommendations based on a 35-year experience. Int J Radiat Oncol Biol Phys 67:1145-1154,2007

12. Lenzi J, Salvati M, Raco A, Frati A, Piccirilli M, Delfini R: Central neurocytoma: A novel appraisal of a polymorphic pathology. Our experience and a review of the literature. Neurosurg Rev 29:286292, discussion 292, 2006

13. Mackenzie IR: Central neurocytoma: Histologic atypia, proliferation potential, and clinical outcome. Cancer 85:1606-1610, 1999
14. Mena H, Morrison AL, Jones RV, Gyure KA: Central neurocytomas express photoreceptor differentiation. Cancer 91:136-143, 2001

15. Milligan BD, Meyer FB: Morbidity of transcallosal and transcortical approaches to lesions in and around the lateral and third ventricles: A single-institution experience. Neurosurgery 67:1483-1496, discussion 1496, 2010

16. Niiro $T$, Tokimura $H$, Hanaya $R$, Hirano $H$, Fukukura $Y$, Sugiyma $K$, Eguchi K, Kurisu K, Yoshioka H, Arita K: MRI findings in patients with central neurocytomas with special reference to differential diagnosis from other ventricular tumours near the foramen of Monro. J Clin Neurosci 19:681-686, 2012

17. Osborn AG: Central neurocytoma. Diagnostic Imaging-BRAIN, 6. Salt Lake City, Utah: Amirsys, 2004:80-83

18. Paek SH, Han J-H, Kim JW, Park C-K, Jung H-W, Park S-H, Kim IH, Kim DG: Long-term outcome of conventional radiation therapy for central neurocytoma. Neurooncol 90: 25-30, 2008

19. Qian H, Lin S, Zhang M, Cao Y: Surgical management of intraventricular central neurocytoma: 92 cases. Acta Neurochir (Wien) 154:1951-1960, 2012

20. Rades D, Fehlauer F: Treatment options for central neurocytoma. Neurology 59:1268-1270, 2002

21. Ramsahye H, He H, Feng X, Li S, Xiong J: Central neurocytoma: Radiological and clinico-pathological findings in 18 patients and one additional MRS case. J Neuroradiol 40:101-111,2013

22. Ren H, Chen X, Sun G, Hu S, Zheng G, Li F, Li J, Xu B: Resection of subependymal giant cell astrocytoma guided by intraoperative magnetic resonance imaging and neuronavigation. Childs Nerv Syst 29:1113-1121, 2013

23. Schild SE, Scheithauer BW, Haddock MG, Schiff D, Burger PC, Wong WW, Lyons MK: Central neurocytomas. Cancer 79:790795, 1997

24. Schmidt MH, Gottfried ON, von Koch CS, Chang SM, McDermott MW: Central neurocytoma: A review. J Neurooncol 66:377-384, 2004

25. Secer HI, Duz B, Izci Y, Tehli O, Solmaz I, Gonul E: Tumors of the lateral ventricle: The factors that affected the preference of the surgical approach in 46 patients. Turk Neurosurg 18:345-355, 2008

26. Sharma MC, Deb P, Sharma S, Sarkar C: Neurocytoma: A comprehensive review. Neurosurg Rev 29:270-285, 2006

27. Takao H, Nakagawa K, Ohtomo K: Central neurocytoma with craniospinal dissemination. J Neurooncol 61:255-259, 2003

28. Zhang B, Luo B, Zhang Z, Sun G, Wen J: Central neurocytoma: A clinicopathological and neuroradiological study. Neuroradiology 46:888-895, 2004 